\title{
Teoremas secretos do Super Bomberman
}

Super Bomberman's secret theorems

\begin{abstract}
Resumo
Não é raro que jogos digitais possuam finais secretos, passagens secretas, personagens secretos... mas quem poderia imaginar que também houvessem teoremas secretos? Reconhecendo a importância de se desenvolver nos cidadãos uma apreciação da Matemática tanto por seus aspectos estéticos como recreativos, identificamos propriedades do jogo digital Super Bomberman que podem ser definidas como teoremas Matemáticos e demonstradas analiticamente. Dessa forma, apresentamos 5 teoremas referentes ao jogo com suas respectivas demonstrações. Esperamos assim contribuir com uma estratégia para produção de materiais replicáveis a diversos jogos digitais, que permitam trazer aos jogadores, acostumados com os ambientes descontraído de um jogo digital recreativo, a mesma Matemática tida como séria e formal dentro da academia.

Palavras-chave: Teoremas. Demonstrações. Jogo Digital.
\end{abstract}

Marcos Henrique de Paula Dias
da Silva
UNESP - Universidade Estadual
Paulista "Júlio de Mesquita Fi-
lho"
calibum@usp.br

\begin{abstract}
It is not uncommon for digital games to have secret endings, secret passages, secret characters... but who could have imagined that there were also secret theorems? Recognizing the importance of developing an appreciation of Mathematics for both its aesthetic and recreational aspects, we have identified properties of the digital game Super Bomberman that can be defined as Mathematical theorems and demonstrated analytically. In this way, we present 5 theorems related to the game with their respective demonstrations. We hope to contribute with a strategy for the production of replicable materials to various digital games, that allow players accustomed to the relaxed environments of a digital recreational game, to have the same serious and formal Mathematics within the academy.
\end{abstract}

Keywords: Theorems. Demonstrations. Digital Game. 


\section{Introdução}

De certo jogar videogame é mais intuitivo do que demonstrar teoremas da Matemática. Como aponta Gee (2005), os jogos digitais de sucesso incorporam da Psicologia importantes princípios de aprendizagem com o objetivo de ensinar aos seus jogadores como jogá-los. $\mathrm{Na}$ contramão aos videogames, demonstrar teoremas pode ser percebida como uma ação puramente abstrata e sem precedentes. Contudo, propor teoremas parece ocupar o meio desta estranha trajetória que liga o jogar videogames à demonstração Matemática, como abordaremos a seguir.

Fellows (1996) discute a rigidez dos jogos digitais e sua semelhança com a Matemática. Em ambos os casos, mediante um novo desafio tratamos primeiro de formular hipóteses. Então, com o acúmulo dos resultados obtidos em testes, começam a aparecer proposições. Estas afirmações tornam os obstáculos triviais. Com isto, surgem fórmulas replicáveis para resolver problemas específicos. Assim, no percurso para a conclusão do jogo temos diversos teoremas que descobrimos e combinamos para desenvolvermos novas proposições.

\begin{tabular}{|c|c|c|}
\hline & Videogames & Matemática \\
\hline Hipóteses & Será que eu morro se cair nesta lava? & Será que o produto de 17 por 41 é par? \\
\hline Proposições & Toda lava é fatal para meu personagem. & Todo o produto de ímpares é ímpar. \\
\hline Aplicabilidade & Aquele trajeto é impossivel de atravessar. & O produto de 117.711 por 591.245 é ímpar. \\
\hline Fórmulas & $\begin{array}{c}\text { Sempre que tiver uma plataforma, posso } \\
\text { me apoiar nela para atravessar a lava. }\end{array}$ & O produto de N ímpares será sempre ímpar. \\
\hline Teoremas & $\begin{array}{c}\text { Posso me apoiar nas plataformas; } \text { Lava é } \\
\text { fatal; Existem plataformas invisíveis. }\end{array}$ & $\begin{array}{c}\text { O produto de M pares será sempre par; O produ- } \\
\text { to de M pares por N ímpares será sempre par. }\end{array}$ \\
\hline
\end{tabular}

Quadro 1 - Semelhança de comportamentos entre jogadores e matemáticos (fonte própria).

Dessa forma, pessoas com muita experiência em jogos digitais aprenderam a se comportar (embora inconscientemente) como pesquisadores matemáticos. Fazendo suposições razoáveis para suas hipóteses, permitindo que ataquem os problemas com eficiência (FELLOWS, 1996). Podemos perceber esta semelhança apresentando a jogadores experientes em um jogo digital uma suposta proposição verdadeira: Toda plataforma é inofensiva ao personagem. Estes, podem provar a falsidade da afirmação nos mostrando um contraexemplo: A plataforma de cor vermelha causa danos ao personagem, logo nem toda plataforma é inofensiva.

Dessa forma, apresentamos este artigo com o intuito de ser ponte entre o jogar e o demonstrar teoremas. Acrescentando uma etapa a mais no comportamento dos jogadores experientes, que se assemelha ao dos pesquisadores matemáticos no que diz respeito ao formalismo e construção das demonstrações de teoremas propostos dentro de jogos digitais. Esperamos assim, desenvolver em um ambiente descontraído de um jogo digital, uma apreciação da Matemática tida como séria ou formal dentro da academia por seus aspectos estéticos e recreativos, como sugerem as recomendações da Principles... (2000). Esta, uma publicação da National Council of Teachers of Mathematics, a maior organização mundial com foco na Educação Matemática, envolvendo ativamente os professores e pesquisadores dos Estados Unidos e do Canadá.

\section{Método}

Para tratarmos da Matemática formal dentro de um jogo digital primeiro foi necessário estabelecer um funcionamento analítico para seus principais componentes. Por esta razão toma-

SILVA, M. H. de P. D. da. Teoremas secretos do Super Bomberman. C.Q.D.- Revista Eletrônica Paulista de Matemática, Bauru, v. 14, p. 1-11, fev. 2019. 
mos como base o trabalho de Silva (2018) que realiza para o jogo digital Super Bomberman ${ }^{1}$ um processo de discretização de componentes ${ }^{2}$. Podemos considerar que este é um jogo digital abrangente o bastante para atingir um grande público de leitores, dado que até 2009 existiam cerca de 70 versões da franquia de Bomberman produzidas, das quais, quase 10 milhões de cópias já tinham sido vendidas (THE COMPLETE..., 2009). Além disto, o fato do próprio pesquisador ser um jogador experiente neste título, o coloca na posição de formular teoremas à medida que joga. Dessa forma, realizamos no próprio ambiente de jogo, uma busca por teoremas que pudessem ser demonstrados analiticamente, excluindo aqueles que aparentemente exigissem demonstrações por exaustão (averiguando toda uma árvore de possibilidades).

\section{Super Bomberman}

O jogo utiliza gráficos bidimensionais com uma leve inclinação para dar aspecto de altura aos personagens, objetos e cenário em dois modos de interação: aventura e batalha. Para evitarmos explicar as muitas variações do primeiro, trataremos aqui somente do modo de batalha.

Os personagens são robozinhos (cada um com uma cor diferente predominante) que se movimentam na horizontal e na vertical através das casas do cenário qufe se encontram desobstruídas. Cada cenário é composto por casas que podem estar ocupadas por bloquinhos indestrutíveis, bloquinhos destrutíveis, personagens, bombas ou itens coletáveis. O conjunto de todas as casas do cenário forma um tabuleiro NxM (usualmente 11x13) com $\mathrm{N}$ e M números naturais ímpares maiores ou iguais a 3 . Considerando a casa localizada no canto inferior esquerdo como a posição $(1,1)$, temos que as posições $(2 \mathrm{n}, 2 \mathrm{~m})$, com $\mathrm{n}, \mathrm{m}$ números naturais, obrigatoriamente correspondem a casas inocupáveis (bloquinhos indestrutíveis), enquanto as demais posições podem estar inocupáveis (bloquinhos indestrutíveis), livres (personagens, itens coletáveis) ou obstruídas momentaneamente (bloquinhos destrutíveis, bombas). Devido aos diversos efeitos que os itens coletáveis podem causar, não trataremos deles neste artigo. Também com o intuito de simplicidade linguística, chamaremos no decorrer deste artigo, de cenários padrões, os tabuleiros nos quais somente as posições $(2 \mathrm{n}, 2 \mathrm{~m})$ sejam inocupáveis.

Para eliminar os bloquinhos destrutíveis neste jogo são utilizadas bombas, que quando colocadas numa posição do cenário, obstruem o trajeto até que explodam, eliminando a si mesma, personagens e bloquinhos destrutíveis em linhas retas livres ao seu redor dentro de uma distância equivalente a sua potência atual. Podemos interpretá-las como funções que dado sua posição atual $(\mathrm{X}, \mathrm{Y})$, com $\mathrm{X}$ e $\mathrm{Y}$ números naturais, sendo j o alcance máximo da explosão (em casas do tabuleiro), no ato da explosão atingem ao mesmo tempo somente as primeiras posições livres em ambos os sentidos da horizontal $(\mathrm{X}+\mathrm{i}, \mathrm{Y})$ e em ambos os sentidos da vertical $(\mathrm{X}, \mathrm{Y}+\mathrm{i})$, tal que $-\mathrm{j}-1<\mathrm{i}<\mathrm{j}+1$. Caso o alcance da explosão seja interrompido por uma bomba, ela detonará a bomba no efeito que chamamos de cadência. A bomba explodida em cadência detonará nas outras três direções livres. Caso o alcance da explosão seja interrompido por um bloquinho destrutível, o bloquinho destrutível será eliminado. Personagens não obstruem explosões.

No modo de batalha, os personagens se enfrentam até restar somente um ou até que tempo limite termine, considerando neste caso um empate para todos os personagens daquele turno. Quando o tempo de batalha chega na metade, o cenário começa a reduzir exigindo que os personagens restantes batalhem mais próximos uns dos outros. Independente da origem da bom-

1 Lançado em 1993, é uma versão de Bomberman, uma série jogos de estratégia baseados em labirintos bidimensionais com visão de topo, desenvolvida por Hudson Soft e com a primeira versão publicada em 1983.

2 Silva (2018) em releitura ao trabalho de Fellows (1996), percebe que para tratar analiticamente as componentes de jogos digitais é preciso, primeiro, organizá-las dentro de estruturas matemáticas mais simples. $\mathrm{O}$ autor associa o processo de simplificar os modelos gerados pela interface gráfica do computador, ao processo na Matemática de transformar funções ou modelos contínuos em análogos com variáveis discretas (discretização).

SILVA, M. H. de P. D. da. Teoremas secretos do Super Bomberman. C.Q.D.- Revista Eletrônica Paulista de Matemática, Bauru, v. 14, p. 1-11, fev. 2019. Edição Ermac.

DOI: 10.21167/cqdvol14ermac201923169664mhpds0111 Disponível em: https://www.fc.unesp.br/\#!/departamentos/matematica/revista-cqd/ 
ba, todas as explosões são fatais a todos os personagens, bloquinhos destrutíveis ou bombas. Quando uma mesma explosão atinge em simultâneo todos os personagens restantes no turno, o jogo determina por seus próprios critérios a ordem em que os personagens foram atingidos. O último a ser atingido neste caso, é o vencedor daquele turno. Abaixo apresentamos, com intuito de ilustrar estas definições, duas cenas do jogo Super Bomberman.
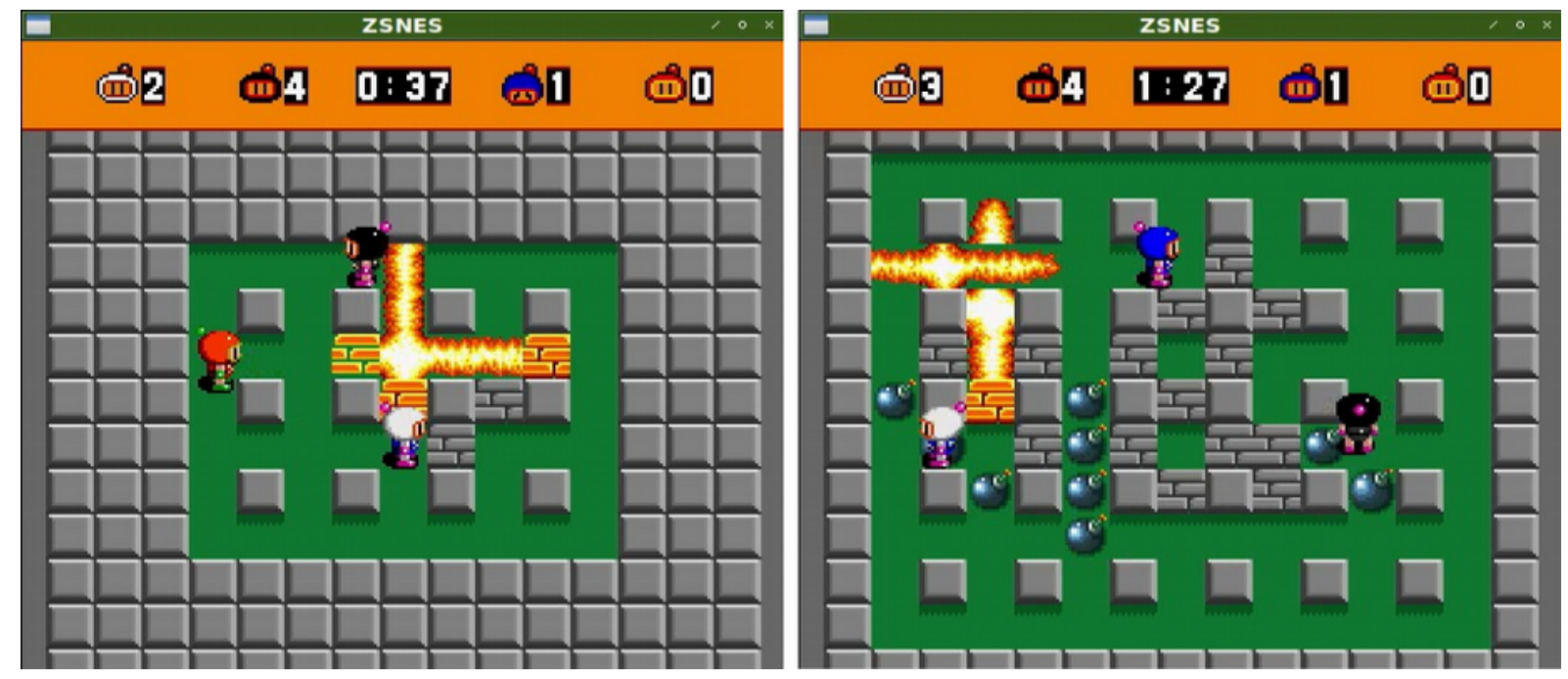

Figura 1 - Exemplos de interações no jogo (fonte própria).

\section{Teoremas}

Sem o intuito de construirmos novos conceitos para a Matemática, apresentamos aqui o fruto de inúmeras partidas jogadas com um olhar crítico. Neste período, percorríamos o mesmo trajeto de jogadores, partindo de hipóteses, analisando-as, replicando-as até chegarmos na formulação de teoremas. Acreditamos que tantos outros jogadores deste título já se depararam com proposições semelhantes, inclusive, sendo capazes de provar quando falsas a partir de contraexemplos. Assim, diante das afirmações identificadas, construímos suas respectivas demonstrações, confirmando assim, que se tratam de teoremas. Os quais apresentamos a seguir:

\subsection{Teorema das explosões cadenciadas}

Para $\mathrm{n}$ bombas colocadas em explosões cadenciadas, com $\mathrm{n}>0$, o máximo de bloquinhos destrutíveis que podem ser atingidos pelas explosões é $2 n+2$. 

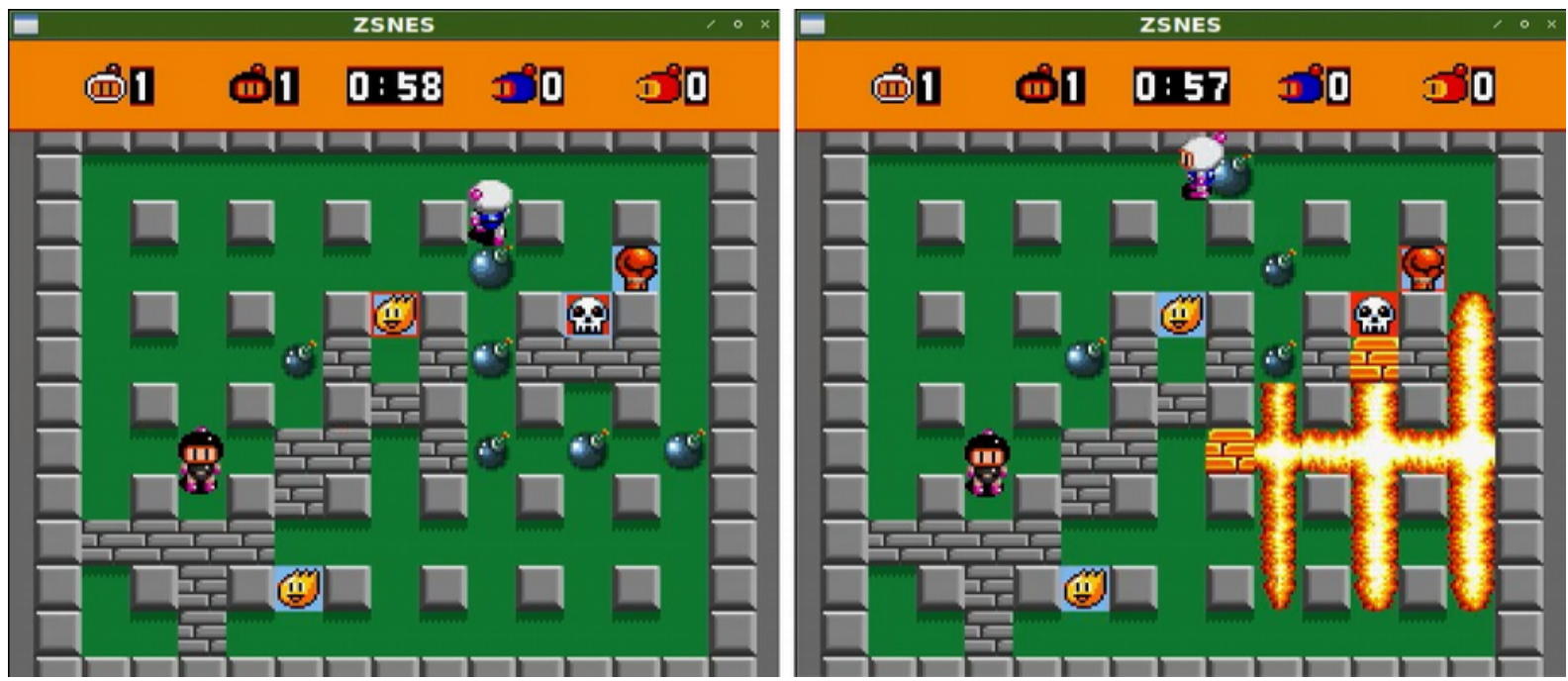

Figura 2 - Exemplo de 5 bombas iniciando cadência (fonte própria).

Demonstração: Por definição a destruição de um bloquinho só ocorre quando a bomba possuí um j (alcance da explosão) suficientemente grande e não é interrompida por outra bomba ou bloquinho indestrutível. Seja $\mathrm{B}_{\mathrm{n}}$ a n-ésima bomba implantada nesta cadência para $\mathrm{n}>0$. Neste caso, para $\mathrm{B}_{1}$, temos a destruição de até 4 bloquinhos destrutíveis, pois sua detonação não é encadeada por nenhuma outra bomba.

Para cada $\mathrm{B}_{\mathrm{m}}$ com $\mathrm{m}>1$, temos que a explosão $\mathrm{B}_{\mathrm{m}}$ só ocorre devido a ter interrompido a explosão de alguma $B_{n}$ com $1<n<m$. Assim para cada $B_{m}$, temos que a trajetória responsável por colocá-la em cadência, foi perdida. De modo análogo, para cada $B_{m}$ temos que a $B_{n}$ responsável por sua cadência teve uma explosão interrompida (para ativar a cadência).

Dessa forma, para $B_{n}$, com $n>0$, temos $n-1$ bombas cadenciadas e $n-1$ explosões utilizadas para gerar suas cadências. Então o total de explosões que podem atingir bloquinhos destrutíveis para cada uma delas fica sendo $4 n-(n-1)-(n-1)=2 n+2$.

\subsection{Teorema da paridade dos bloquinhos destrutíveis}

Sendo nos cenários padrões uma face delimitada por bloquinhos destrutíveis e afastada da fronteira, considerando como vértices os bloquinhos indestrutíveis e como arestas internas as laterais dos bloquinhos destrutíveis que podem ser alcançadas por um personagem em seu interior. Todas as faces afastadas da fronteira das quais cada aresta interna está associada a um único bloquinho destrutível, são delimitadas por um número par de bloquinhos destrutíveis. 

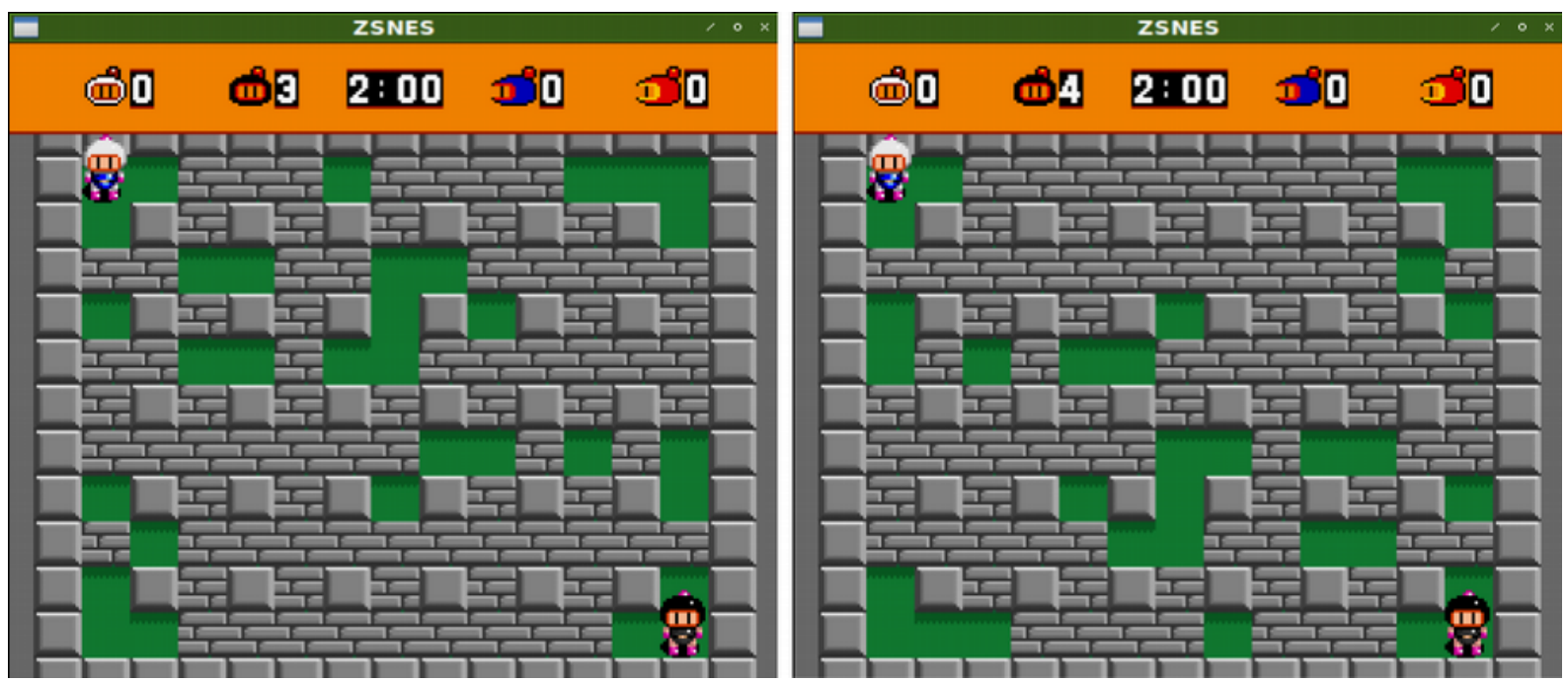

Figura 3 - Exemplos de faces nas condições do teorema (fonte própria).

Demonstração: Sem perda de generalidade, podemos desconsiderar os vértices exteriores a esta face. Os vértices que formam as arestas interiores serão chamados de vértices interiores, e os vértices dentro da face mas sem contato com nenhum bloquinho destrutível serão chamados de vértices solitários. Assim, toda aresta interior está conectada com exatamente dois vértices interiores, e todo vértice interior está conectado com exatamente duas arestas interiores, logo existe o mesmo número de arestas interiores que vértices interiores.

Suponhamos que exista uma face formada por um $\mathrm{N}$ ímpar de vértices interiores, mas pela distribuição dos bloquinhos indestrutíveis nos cenários padrões, $(2 \mathrm{~m}, 2 \mathrm{n})$, isto é impossível pela inexistência de conexões diagonais. Pois ignorando os vértices exteriores à face, somente devemos nos preocupar com as conexões diagonais no interior da face, mas elas por sua vez não podem existir por definição, visto que teríamos um bloquinho destrutível conectado a um vértice solitário, transformando este em um vértice interior, implicando um mesmo bloquinho associado a mais de uma aresta interior. Logo, absurdo.

\subsection{Teorema da máxima dominância de bombas}

Em um cenário padrão NxM vazio de obstruções, com j (alcance da explosão) suficientemente grande, podemos explodir todos os espaços com no mínimo $(\operatorname{Max}(\mathrm{N}, \mathrm{M})+3) / 2$ bombas.
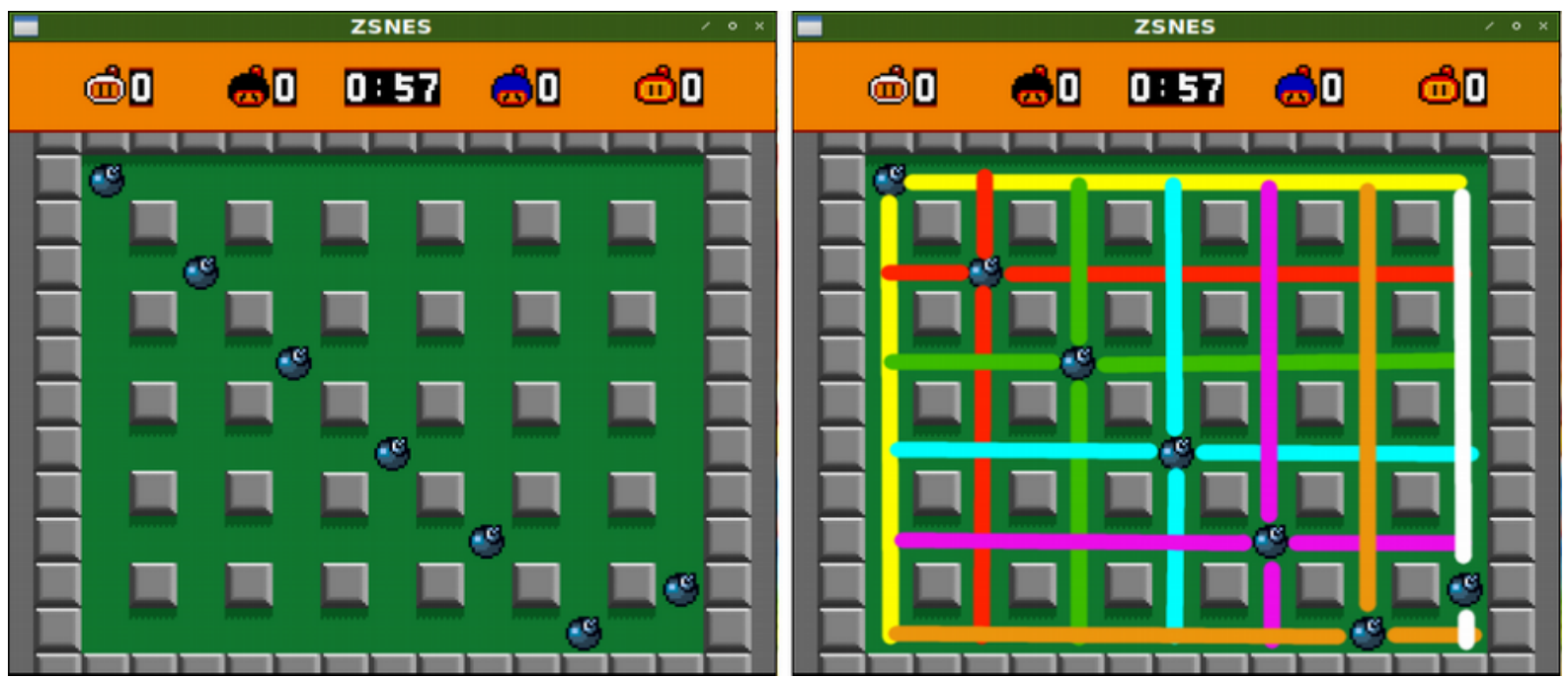

Figura 4 - Exemplo de dominância do cenário padrão 11x13 (fonte própria).

SILVA, M. H. de P. D. da. Teoremas secretos do Super Bomberman. C.Q.D.- Revista Eletrônica Paulista de Matemática, Bauru, v. 14, p. 1-11, fev. 2019. Edição Ermac.

DOI: 10.21167/cqdvol14ermac201923169664mhpds0111 Disponível em: https://www.fc.unesp.br/\#!/departamentos/matematica/revista-cqd/ 
Demonstração: Seja K o máximo de $M$ e N. Vamos primeiro mostrar que com $(\mathrm{K}+3) / 2$ bombas é possível explodir todas as posições, depois mostraremos que $(\mathrm{K}+3) / 2$ é o mínimo. Com $n, m$, x e y números naturais, temos que:

$\mathrm{Se} \mathrm{N}<\mathrm{M}$, tomemos com bombas tanto a diagonal dos pontos $(2 \mathrm{n}-1,2 \mathrm{n}-1) \operatorname{com} 0<\mathrm{n}<(\mathrm{N}+3) /$ 2 como as posições $(2, \mathrm{~m})$, para $(\mathrm{N}+1) / 2<\mathrm{m}<(\mathrm{M}+3) / 2$. Todas as posições livres do cenário padrão podem ser descritas como (x, $2 \mathrm{n}-1)$ ou $(2 \mathrm{n}-1, \mathrm{y})$ ou $(\mathrm{m}, \mathrm{y})$.

$\mathrm{Se} \mathrm{N}=\mathrm{M}$, tomemos com bombas a diagonal dos pontos $(2 \mathrm{n}-1,2 \mathrm{n}-1)$ com $0<\mathrm{n}<(\mathrm{N}+3) / 2$. Todas as posições livres do cenário padrão podem ser descritas como (x, 2n-1) ou (2n-1, y).

$\mathrm{Se} \mathrm{N}>\mathrm{M}$, tomemos com bombas tanto a diagonal dos pontos $(2 \mathrm{n}-1,2 \mathrm{n}-1)$ com $0<\mathrm{n}<(\mathrm{M}+3) / 2$ como as posições $(\mathrm{m}, 2)$, para $(\mathrm{N}+1) / 2>\mathrm{m}>(\mathrm{M}+3) / 2$. Todas as posições livres do cenário padrão podem ser descritas como $(\mathrm{x}, 2 \mathrm{n}-1)$ ou $(2 \mathrm{n}-1, \mathrm{y})$ ou $(\mathrm{x}, \mathrm{m})$.

Assim, como j é suficientemente grande, nos três casos, o alcance das explosões atinge quaisquer das posições possíveis do cenário padrão.

Agora vamos supor que seja possível atingir todas as posições com menos de $(K+3) / 2$ bombas. Fixando $\mathrm{K}$ como o máximo de linhas ou colunas, se eliminássemos $\mathrm{K}$ linhas ou $\mathrm{K}$ colunas que possuam bloquinhos indestrutíveis, teríamos um cenário vazio com $(\mathrm{K}+3) / 2$ linhas ou colunas. Mas por definição, cada bomba explode uma linha e uma coluna em ambos os sentidos $(\mathrm{X}+\mathrm{i}, \mathrm{Y})$ e $(\mathrm{X}, \mathrm{Y}+\mathrm{i})$, tal que $-\mathrm{j}-1<\mathrm{i}<\mathrm{j}+1$. Assim, temos ao menos $(\mathrm{K}+3) / 2$ linhas ou colunas a serem explodidas, com isto, precisaremos de no mínimo $(\mathrm{K}+3) / 2$ bombas.

\subsection{Teorema da unicidade das explosões}

Com o personagem localizado em um canto da tela em segurança para implantar ao menos uma bomba, com $\mathrm{j}>1$, é possível explodir todos os bloquinhos destrutíveis da tela, destruindo exatamente um a cada explosão.

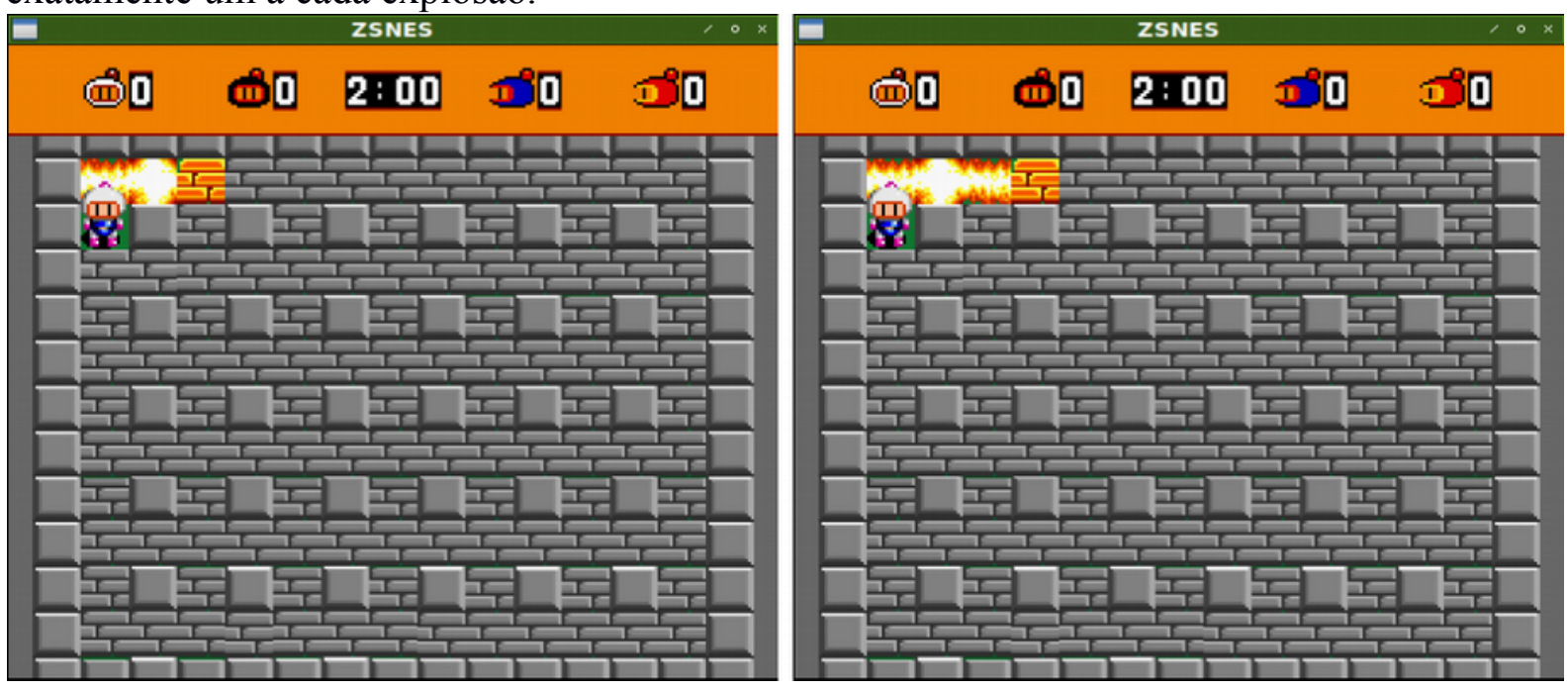

Figura 5 - Exemplo do pior caso para o cenário padrão 11x13 (fonte própria).

Demonstração: Sem perda de generalidade, vamos assumir que o personagem comece com o canto $(1,1)$ e as posições adjacentes $(1,2)$ e $(2,1)$ livres. Chamaremos de $G_{n}$ o conjunto de bloquinhos destrutíveis que ocupam a linha e coluna com intersecção em (n, n). Tomemos então o pior caso possível, ou seja, onde apenas as posições $(1,1),(1,2)$ e $(2,1)$ estejam livres. Para resolvê-lo, podemos aplicar o seguinte algoritmo.

1. Começando com $n$ igual a 1 , avance para $G_{n+1}$ somente quando $G_{n}$ estiver livre de bloquinhos destrutíveis;

2. Se n é ímpar, então coloque bombas em $\mathrm{G}_{\mathrm{n}}$ nas posições adjacentes aos bloquinhos indestrutíveis de $\mathrm{G}_{\mathrm{n}+1}$;

SILVA, M. H. de P. D. da. Teoremas secretos do Super Bomberman. C.Q.D.- Revista Eletrônica Paulista de Matemática, Bauru, v. 14, p. 1-11, fev. 2019. 
3. Se $\mathrm{n}$ é par, então coloque bombas em $\mathrm{G}_{\mathrm{n}=1}$ nas posições adjacentes aos bloquinhos indestrutíveis de $\mathrm{G}_{\mathrm{n}-1}$;

4. Se $G_{m}$ para algum $m>n$, tiver bloquinhos destrutíveis, volte para o passo 1 .

\subsection{Teorema do máximo número de personagens}

Para que um personagem na posição $(\mathrm{N}, \mathrm{M})$ esteja em segurança no campo ele precisa ter livre acesso a pelo menos uma das seguintes posições: $(\mathrm{N}, \mathrm{M}+1)$ e $(\mathrm{N}+1, \mathrm{M}) ;(\mathrm{N}, \mathrm{M}+1)$ e $(\mathrm{N}-$ $1, \mathrm{M}) ;(\mathrm{N}, \mathrm{M}-1)$ e $(\mathrm{N}+1, \mathrm{M}) ;(\mathrm{N}, \mathrm{M}-1)$ e $(\mathrm{N}-1, \mathrm{M})$. Os personagens somente estarão isolados se não houverem dois ou mais personagens ocupando uma mesma face. Assim, o número máximo de personagens que podem começar em segurança e isolados uns dos outros para qualquer cenário padrão $\mathrm{MxN}$ ou $\mathrm{NxM}$, sendo $\mathrm{M}$ e $\mathrm{N}$ ímpares, para $\mathrm{N}$ da forma $2 \mathrm{n}-1$, é dado por:

1. $\mathrm{kn}, \mathrm{se} \mathrm{M}$ é da forma $4 \mathrm{k}-1$;

2. $(\mathrm{kn})+(\mathrm{n}+1) / 2$, se $\mathrm{M}$ é da forma $4 \mathrm{k}+1$.
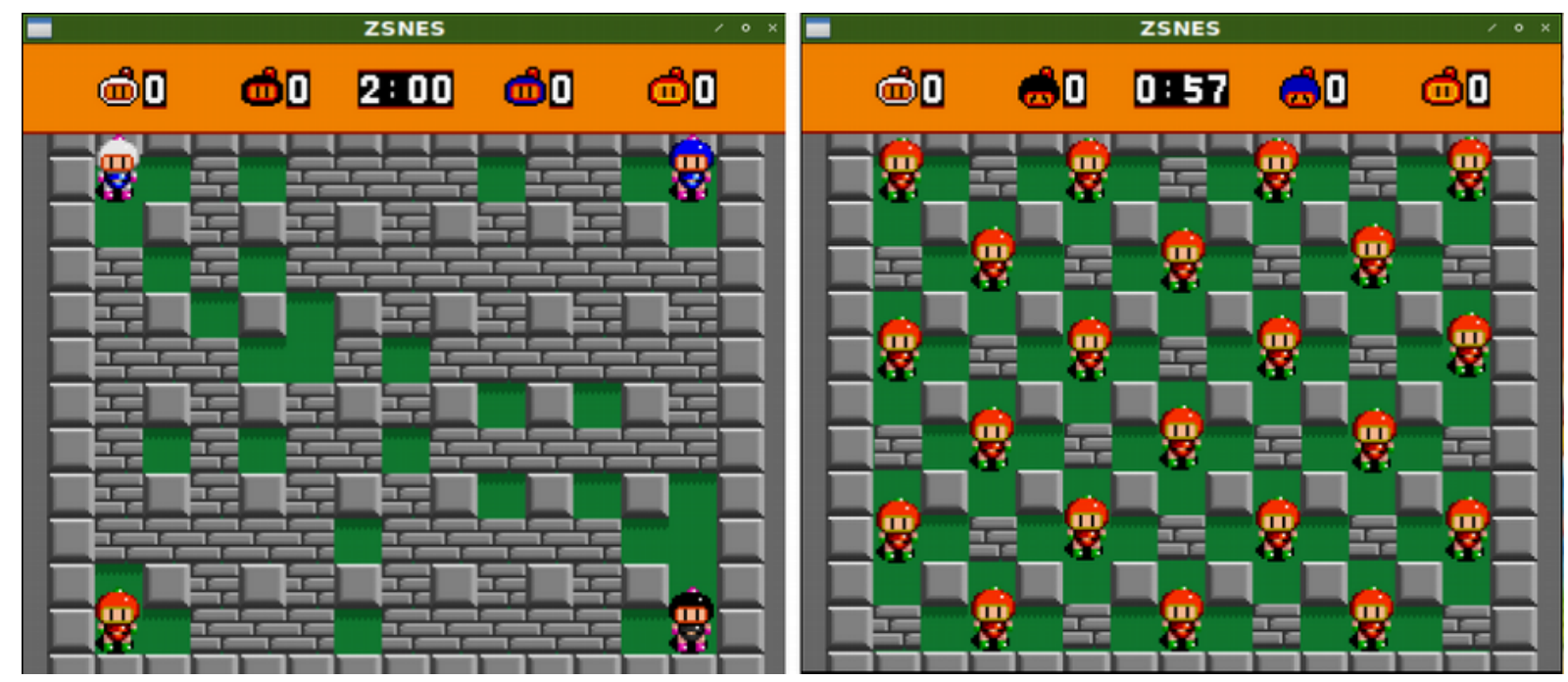

Figura 6 - Exemplos de distribuição de personagens no cenário padrão 11x13 (fonte própria).

Demonstração: Neste caso, no cenário padrão mínimo, ou seja, um tabuleiro 3x3, o número máximo de personagens é 2 . Pois o ponto $(2,2)$ por definição é ocupado pelo bloquinho indestrutível. Também por definição, os personagens para serem considerados seguros não podem ocupar pontos adjacentes aos bloquinhos indestrutíveis. Por último, os personagens não poderão ter os pontos de acesso livres iguais, senão implicaria que eles ocupam a mesma face, logo não se encontram isolados.

Mantendo a relação de isolamento e segurança para cada personagem, vemos que ao fixarmos $\mathrm{M}$ igual a 3, e aumentarmos $\mathrm{N}$, temos para cada 2 espaços que o cenário aumenta em $\mathrm{N}$, surge espaço para mais um personagem ser inserido. Assim, em Nx3 para $n$ da forma $2 n-1$, cabem n personagens. Dessa forma, se n é par, a cada dois espaços que aumentamos em $\mathrm{M}$, surgem espaço para $\mathrm{n} / 2$ novos personagens. Por outro lado, se $\mathrm{n}$ é ímpar, a cada dois espaços que aumentamos, surge espaço para $(n+1) / 2$ personagens.

Assim, n será par quando $\mathrm{N}$ puder ser escrito na forma 4k-1, e n será ímpar quando $\mathrm{N}$ puder ser escrito na forma $4 \mathrm{k}+1$. Então, se $\mathrm{N}$ ou $\mathrm{M}$ puderem ser escritos na forma $4 \mathrm{k}-1$, em $\mathrm{NxM}$ a menos de rotações, haverá espaço para kn personagens. Por outro lado, se $\mathrm{N}$ e M puderem ser escritos na forma $4 \mathrm{k}+1$, então podemos considerar o caso anterior mais 2 espaços acrescidos em uma direção, ou seja, $\mathrm{Nx}(\mathrm{M}-2)+(\mathrm{n}+1) / 2$, que é igual a $\mathrm{kn}+(\mathrm{n}+1) / 2$ personagens. 


\section{Bônus}

É comum aos jogos digitais que existam bônus para os jogadores dedicados. Assim, neste artigo também apresentamos um bônus aos leitores assíduos. Dessa vez, não um teorema proposto a partir de métricas do jogo, mas uma aplicação de um famoso teorema a um caso do jogo. Um teorema fundamental para a teoria das probabilidades, conhecido como a Lei dos grandes números propõe que a média aritmética dos resultados da mesma experiência repetidas vezes tende a se aproximar do valor esperado à medida que mais a realizamos. Ou seja, quanto mais tentativas fizermos, mais a probabilidade da média aritmética dos resultados observados se aproximará da probabilidade real.

Para aplicar este teorema ao jogo, supomos o seguinte evento: Em uma batalha contra um personagem controlado pela inteligência artificial do computador de nível 10, em um cenário padrão com 11x13 espaços, começando na posição $(11,1)$ e com o personagem adversário no canto oposto $(1,13)$. Se aguardarmos na casa $(9,3)$ até o fim do jogo, tendo avançado pela mais curta trajetória superior disponível, temos probabilidade de vitória em $60 \%$.
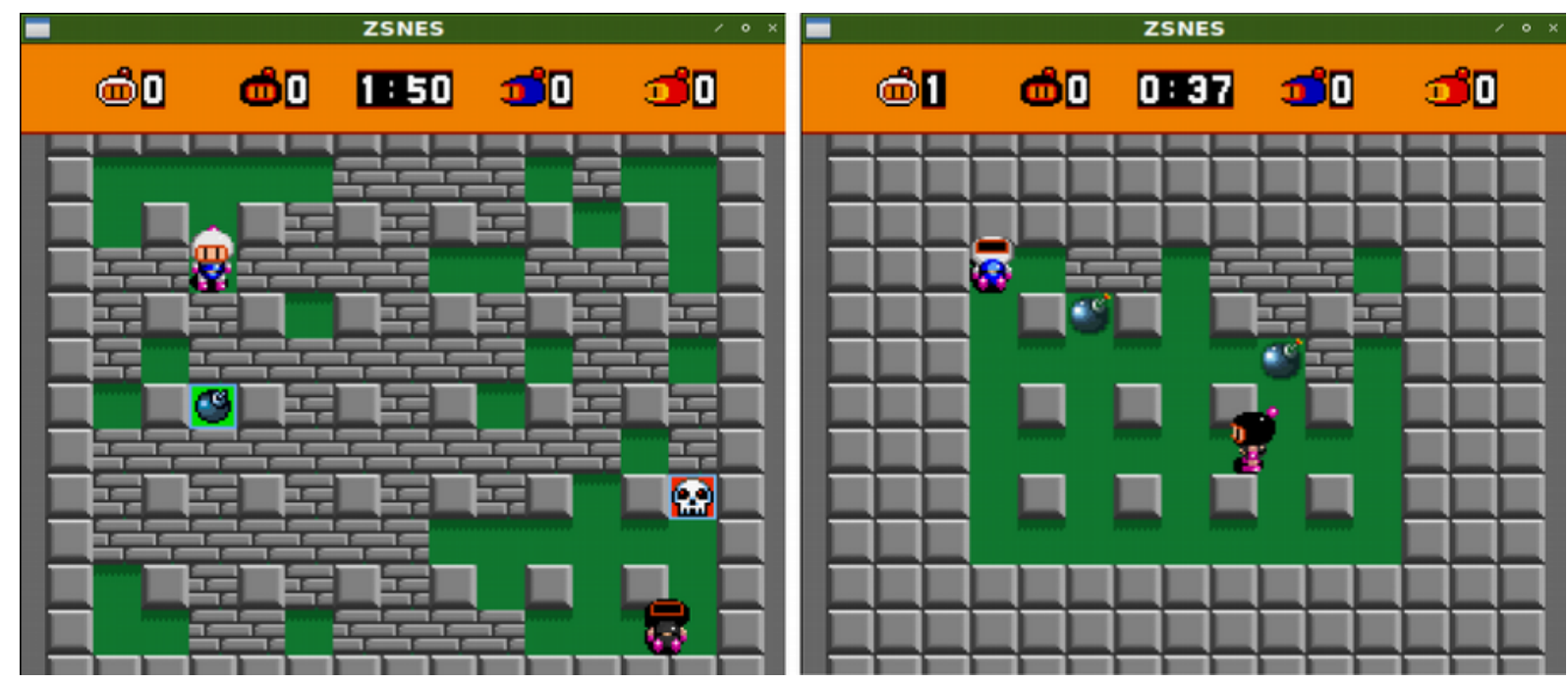

Figura 7 - Exemplo de eventos com vitória e derrota ao personagem branco (fonte própria).

O evento foi realizado ao todo 100 vezes. No gráfico abaixo podemos perceber como a média aritmética dos resultados se aproxima ao longo dos testes de um valor próximo a $60 \%$.

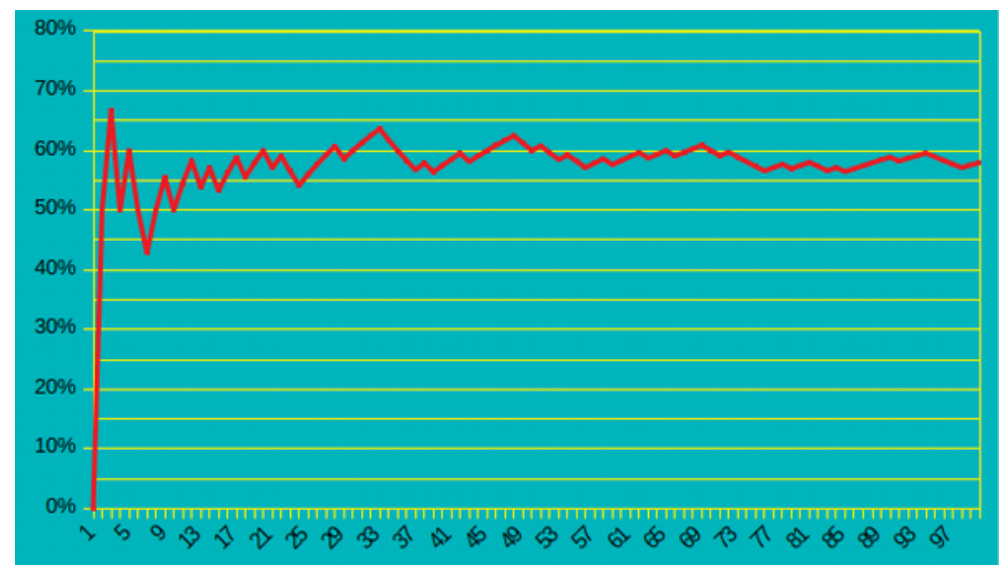

Figura 8 - Porcentagem média das vitórias pelo número de testes (fonte própria).

SILVA, M. H. de P. D. da. Teoremas secretos do Super Bomberman. C.Q.D.- Revista Eletrônica Paulista de Matemática, Bauru, v. 14, p. 1-11, fev. 2019. 
Aproveitando as mesmas condições de teste, tratamos também o tempo médio para sermos eliminados em cada round (na média de 80 segundos) e o tempo médio para que o computador se autodestrua, visto que não estamos efetivamente jogando (na média de 50 segundos). Com o registro dos tempos das mesmas 100 vezes que realizamos o primeiro teste, podemos perceber no gráfico abaixo a convergência dos resultados para os respectivos tempos de morte dos personagens branco (o nosso) e preto (controlado pelo computador) considerando as linhas do gráfico nas mesmas cores de cada personagem (branco ou preto).

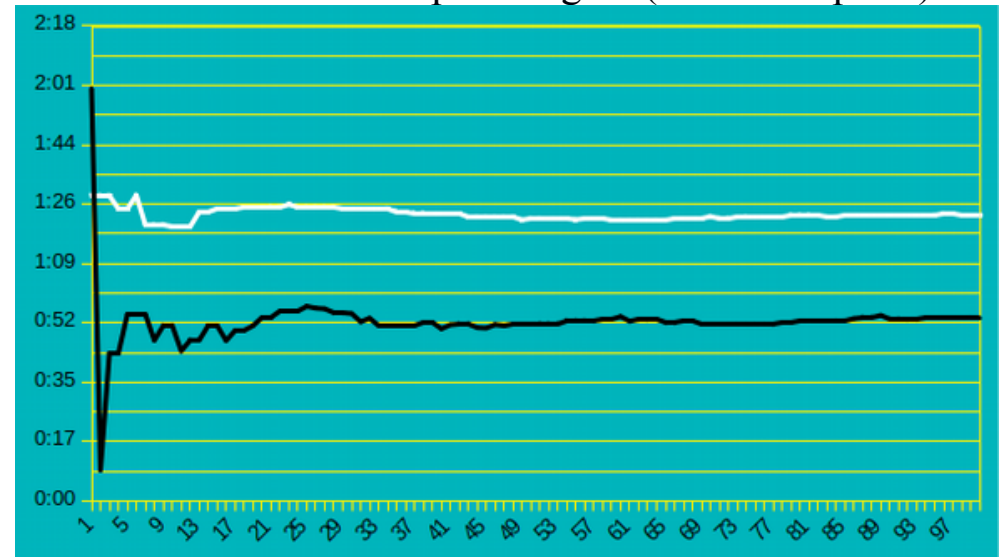

Figura 9 - Tempo médio de vida dos personagens pelo número de testes (fonte própria).

\section{Considerações}

Este é um artigo bastante simples, mas com ele esperamos alcançar tanto aos matemáticos como aos jogadores experientes. Para isto apresentamos uma abordagem de investigação possível dentro de proposições construídas nos jogos digitais e como estas podem ser demonstradas para casos gerais com um certo grau de formalismo.

Percebemos como principal potencial para este material e estudos correlatos, o uso na divulgação científica da Matemática a partir de gêneros de jogos digitais de ampla divulgação. Assim, o mesmo raciocínio de propor hipóteses, construir proposições, formular teoremas e então demonstrá-los, pode ser aplicado aos diversos títulos de jogos digitais recreativos.

\section{Referências}

FELLOWS, M. R. The heart of puzzling: mathematics and computer games. In: COMPUTER GAMES DEVELOPERS CONFERENCE, 10., 1996, Santa Clara, CA. Proceedings... San Francisco, CA: Miller Freeman, c1996, p. 109-120.

GEE, J. P. Good video games and good learning. Phi Kappa Phi Forum, v. 85, n. 2, p. 33$37,2005$.

PRINCIPLES and standards for school mathematics. Reston, VA: National Council of Teachers of Mathematics, c2000.

SILVA, M. H. P. D. A matemática no coração dos jogos digitais: uma releitura do trabalho de Michael R. Fellows. In: ENCONTRO REGIONAL DE MATEMÁTICA APLICADA E COMPUTACIONAL, 5., 2018, Bauru. Caderno de trabalhos completos e resumos. Bauru: Unesp, Faculdade de Ciências, 2018. p. 17-23. Disponível em: $<$ http://www.fc.unesp.br/\#!/de-

SILVA, M. H. de P. D. da. Teoremas secretos do Super Bomberman. C.Q.D.- Revista Eletrônica Paulista de Matemática, Bauru, v. 14, p. 1-11, fev. 2019. 
partamentos/matematica/eventos2341/ermac-2018/caderno-de-trabalhos-e-resumos/>. Acesso em: 05 nov. 2018.

THE COMPLETE history of Bomberman. Retro Gamer, n. 67, p. 27-34, 2009. 